\title{
Erratum to: Neural correlates of correct and failed response inhibition in heavy versus light social drinkers: an fMRI study during a go/no-go task by healthy participants
}

\author{
Salvatore Campanella ${ }^{1}$ - Julie Absil ${ }^{2}$ - Carina Carbia Sinde ${ }^{3} \cdot$ Elisa Schroder $^{1}$. \\ Philippe Peigneux $^{4}$ - Mathieu Bourguignon ${ }^{5,6} \cdot$ Mathieu Petieau $^{7}$. Thierry Metens ${ }^{2}$. \\ Mustapha Nouali $^{2} \cdot$ Serge Goldman $^{5} \cdot$ Guy Cheron $^{7} \cdot$ Paul Verbanck $^{1} \cdot$ Xavier De Tiège $^{5}$
}

Published online: 6 December 2016

(C) Springer Science+Business Media New York 2016

\section{Erratum to: Brain Imaging and Behavior (2016) \\ DOI 10.1007/s11682-016-9654-y}

Unfortunately, there are errors in the name of two authors in the original publication of the article. Xavier Detiège should be changed to Xavier De Tiège, where De Tiège is the last name, and Carbia Sinde should be captured as the last name for Carina Carbia Sinde. The original article was corrected.

The online version of the original article can be found at doi:10.1007 /s11682-016-9654-y

Salvatore Campanella

salvatore.campanella@chu-brugmann.be;

salvatore.campanella@ulb.ac.be

1 Laboratoire de Psychologie Médicale et d'Addiction, ULB Neuroscience Institute (UNI), Université Libre de Bruxelles (ULB), Place Vangehuchten, B-1020 Brussels, Belgium

2 Department of Radiology, ULB-Hôpital Erasme, Université Libre de Bruxelles (ULB), Brussels, Belgium

3 Department of Clinical Psychology and Psychobiology, University of Santiago de Compostela, Santiago de Compostela, Galicia, Spain
$4 \quad$ Neuropsychology and Functional Neuroimaging Research Unit (UR2NF) at Centre de Recherches en Cognition et Neurosciences (CRCN), ULB Neuroscience Institute (UNI), Université Libre de Bruxelles (ULB), Brussels, Belgium

5 Laboratoire de Cartographie fonctionnelle du Cerveau, ULB Neuroscience Institute (UNI), Université Libre de Bruxelles (ULB), Brussels, Belgium

6 BCBL, Basque Center on Cognition, Brain and Language, San Sebastian, Spain

7 Laboratory of Neurophysiology andMovement Biomechanics, ULB Neuroscience Institute (UNI), Université Libre de Bruxelles (ULB), Brussels, Belgium 